\title{
Non-Vital Tooth Bleaching Techniques: A Systematic Review
}

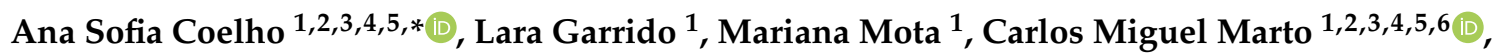 \\ Inês Amaro ${ }^{1}$, Eunice Carrilho ${ }^{1,2,3,4,5}$ (D) and Anabela Paula 1,2,3,4,5 \\ 1 Institute of Integrated Clinical Practice, Faculty of Medicine, University of Coimbra, 3000 Coimbra, Portugal; \\ laragarrido123@gmail.com (L.G.); marianamota1234@gmail.com (M.M.); cmiguel.marto@uc.pt (C.M.M.); \\ ines.amaros@hotmail.com (I.A.); eunicecarrilho@gmail.com (E.C.); anabelabppaula@sapo.pt (A.P.) \\ 2 Coimbra Institute for Clinical and Biomedical Research (iCBR), Faculty of Medicine, University of Coimbra, \\ 3000 Coimbra, Portugal \\ 3 Center for Innovative Biomedicine and Biotechnology, University of Coimbra, 3000 Coimbra, Portugal \\ 4 CIMAGO-Center of Investigation on Enviromnent, Genetics and Oncobiology, Faculty of Medicine, \\ University of Coimbra, 3000 Coimbra, Portugal \\ 5 CNC.IBILI, University of Coimbra, 3000 Coimbra, Portugal \\ 6 Experimental Pathology Institute, Faculty of Medicine, University of Coimbra, 3000 Coimbra, Portugal \\ * Correspondence: anasofiacoelho@gmail.com
}

Received: 12 December 2019; Accepted: 7 January 2020; Published: 9 January 2020

\begin{abstract}
This systematic review aimed to describe and characterize internal tooth bleaching techniques, conventional (walking-bleach) and combined (inside-outside), referring to their efficacy. The research was conducted on the main databases: PubMed, Cochrane Library, EMBASE, and Web of Science. Only randomized controlled trials and cohort studies were considered, on humans of 18 years old or older. A Population, Intervention, Comparison, Outcome (PICO) question was designed to evaluate the scientific evidence. The quality of each randomized controlled trial and cohort study was evaluated using the Cochrane Handbook for Systematic Reviews of Interventions and the Methodological Index for Non-Randomized Studies (ROBINS-I), respectively. The walking-bleach and the combined techniques were both effective at the end of the treatment, obtaining similar aesthetic results. Regardless of the technique used, internal tooth bleaching is an effective procedure, with good aesthetic results, in the treatment of non-vital teeth. The cervical barrier is a standard of care in internal bleaching techniques and should be used. Considering the similarity in the esthetic results obtained in both techniques, the concentrations used for both, and since the biocompatibility of the bleaching agent is more important than its efficiency or speed in obtaining results, the combined technique should be considered the method of choice rather than the walking-bleach technique.
\end{abstract}

Keywords: tooth bleaching; tooth discoloration; non-vital tooth

\section{Introduction}

Currently aesthetics is a field of growing importance, particularly having an aesthetic smile since it has a psychosocial impact and influences the individual's esthetic self-perception. The impact of pigmented teeth is greater when an isolated chromatic change occurs, as the discrepancy with the remaining teeth becomes more obvious [1-3].

Non-vital tooth discoloration may have many causes, namely dental trauma, presence of necrotic debris on the pulp horns and dentinal tubules, poor irrigation, or sealing materials located in the pulp chamber or chamber walls $[4,5]$. The most commonly described cause is intracoronal blood decomposition. Hemolysis of erythrocytes in the dentin tubules is accompanied by the release of iron. 
This, combined with hydrogen sulfate, forms ferric sulfide, a black compound, responsible for the discoloration of the tooth [4-6].

Internal tooth bleaching is a minimally invasive, conservative, relatively simple, effective, and low-cost method in the treatment of discolored endodontically treated teeth. There are several internal tooth bleaching techniques, the most common being the walking-bleach technique, first described by Spasser [7], in 1961. Other techniques include the thermocatalytic technique and the inside-outside technique. The walking-bleach, or conventional, technique consists of inserting the bleaching agent(s) into the pulp chamber, closing the access cavity with a temporary filling, and the dentist refreshing the bleaching agent(s) on a weekly basis until a satisfactory color is achieved $[6,8]$. The thermocatalytic technique is similar to the conventional technique. However, the thermocatalytic method uses various heat forms in order to accelerate the release of reactive oxygen species. Currently this technique is not advisable since heat can damage periodontal tissue and lead to root resorptions $[4,5]$.

The inside-outside, or combined, technique was proposed by Settembrini in 1997 [9], and consists of simultaneous internal and external bleaching, with the use of a custom-fitted tray. In this technique, the access cavity remains open and the patient is responsible for replacing the bleaching agent daily. Therefore, the whitening effect relies on patient compliance $[4,10]$.

Hydrogen peroxide, carbamide peroxide, and sodium perborate are the most commonly described bleaching agents in the literature. These three agents promote reversion of the chromatic change through oxidative reactions $[11,12]$ There are risks associated with non-vital teeth bleaching, such as penetration of hydrogen peroxide in the dentinal tubules, changes in the dentin structure and permeability, general weakening of the physical properties of dental hard tissues, dental fracture during treatment, over-bleaching, possibility of relapse, and, the most serious, external cervical root resorption. Presumably, the diffusion of hydrogen peroxide through the dentinal tubules and microperforations of the cement to the cervical periodontal ligaments is responsible for the destruction of the hard tissues at the level of the cementoenamel junction, due to local necrosis, inflammation, and, consequently, root resorption. Risk of resorption seems to be associated with thermocatalytic techniques and hydrogen peroxide concentrations greater than $30 \%$ as well as prolonged exposure time. For this reason, the use of hydrogen peroxide and thermocatalytic methods has declined [6,13-16].

Currently, there are few studies and little scientific evidence available about the internal tooth bleaching techniques, their efficacy and clinical safety. There is also a lack of a consensual protocol for whitening of non-vital teeth. Thus, this systematic review aims to describe and characterize conventional and combined internal bleaching techniques, regarding their effectiveness and safety.

\section{Materials and Methods}

For this systematic review, a search was performed in the following electronic databases: PubMed (www.ncbi.nlm.nih.gov/pubmed), Cochrane Library (www.cochranelibrary.com), Web of Science (www.webofscience.com), and Embase (www.embase.com)—Table 1.

The research was limited to articles in English, Spanish, and Portuguese, published until 30 December 2019. Only cohort studies and randomized controlled trials on humans of 18 years old or older were included. The application of a tooth bleaching product had to be carried out on non-vital teeth, regardless of the baseline shade and the authors had to measure color change using a shade guide or a color measurement device. The defined exclusion criteria were review articles, in vitro or ex vivo studies, letters to the editor, clinical cases, comments, and studies that included individuals with teeth stained because of smoking or tetracycline. Articles whose abstracts were unavailable online were also excluded.

To evaluate the scientific evidence, a PICO (Population, Intervention, Comparison, Outcome) strategy was defined, and is presented in Table 2. 
Table 1. Search strategy used for selection of scientific evidence.

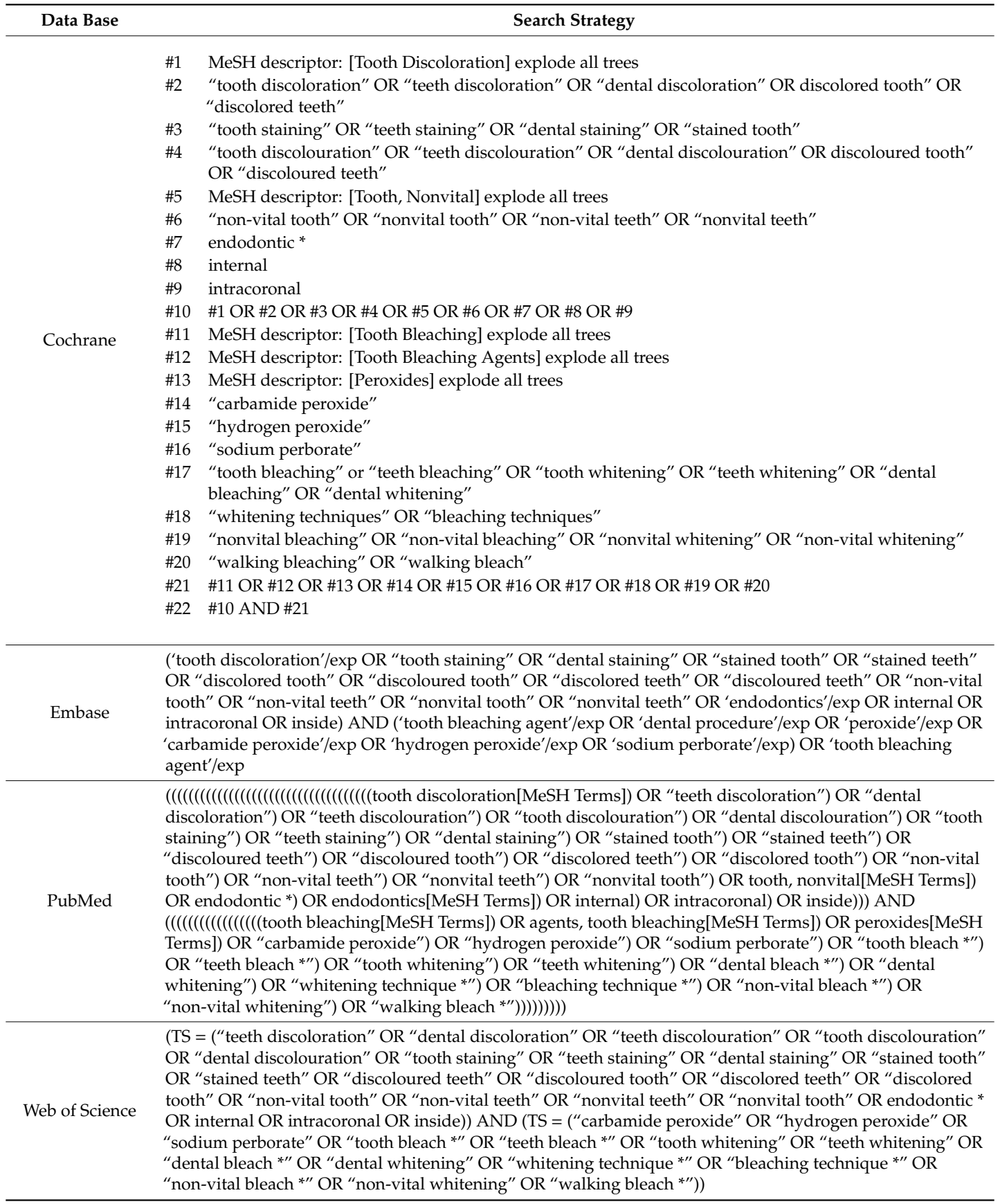

Table 2. Population, Intervention, Comparison, Outcome (PICO) strategy.

\begin{tabular}{cc}
\hline Population $(\mathrm{P})$ & In darkened teeth with endodontic treatment: \\
Intervention $(\mathrm{I})$ & which bleaching technique (walking-bleach or combined) \\
Comparison $(\mathrm{C})$ & is more effective and safe \\
Outcome $(\mathrm{O})$ & for the success of long-term therapy? \\
\hline
\end{tabular}

The titles and abstracts were first examined by two reviewers in order to select the relevant articles. Selection of the eligible studies was performed by the same two reviewers and opinions of a third reviewer were called upon in ambiguous cases. Additional articles were included by analyzing the references of the selected articles. When multiple articles describing the same population were found, the most recent one was reported. 
The studies that fulfilled the inclusion criteria were processed for the extraction of data. The data were as follows: name of the first author, year of publication, type of bleaching intervention with the whitening agent and the protocol, sample size, duration of follow-up, and clinical results. The extraction of the information was done by two independent authors using a standard form.

The quality assessment of the studies included is essential for understanding the results of the systematic review. The quality of each randomized clinical trial was assessed using the bias risk assessment tool described in the Cochrane Handbook for Systematic Reviews of Interventions (version 5.1.0) [17]. The reviewers categorized the following seven quality items as low (low risk of bias), "uncertain" (uncertain risk of bias), or "high" (high risk of bias): random sequence generation, allocation concealment, blinding of participants and researchers, blinding of outcome, incomplete outcome results, selective outcome reporting, and other sources of bias. The risk level of each study was then classified as low (all quality items with low risk), medium (one or two quality items with high and/or uncertain risk), or high (three or more items with high risk and/or uncertain).

Regarding cohort studies, the quality assessment was made using the methodological index for non-randomized studies (ROBINS-I). For this index, seven domains were evaluated in three phases: pre-intervention (bias due to confounding and bias in selection of participants into the study) and (2) at intervention (biases in classification of interventions) and post-intervention (bias due to deviations from intended interventions, bias due to missing data, bias in measurement of outcomes, and bias in selection of the reported results). The risk level of each domain was then classified as low, moderate, serious, or critical according to each study's classification regarding each different bias ((Y) Yes; (PY) probably yes; (PN) probably no; (N) no; and (NI) no information).

Due to the disparity of methodology, it was not possible to perform a quantitative analysis (meta-analysis).

\section{Results}

The flow diagram of study selection is shown in Figure 1. From the initial search, 8049 articles were identified. After eliminating the duplicates and sorting by title and abstract, 8023 records were excluded. The full text of the 26 remaining studies was read. Eighteen articles were excluded as they were in vitro studies, ex vivo studies, trials in children/adolescents, did not measure tooth color with a shade guide or a color measurement device, or were articles describing the same population. No additional articles were included after analyzing the references of the selected articles. Thus, a total of eight studies $[8,13,14,18-22]$ were included in this review.

\subsection{Study Characteristics}

The minimum age included was 18 years [8,18-20] and the maximum was 65 [18]. The sample size varied between eight [13] and 41 [21]. Four articles reported on a minimum baseline shade (using a Vita scale) as inclusion criteria: two [13,18] reported A2 as a baseline shade and two [20,22] reported A3. Four $[8,14,20,21]$ used a Vita shade guide for evaluating color change and three $[13,19,22]$ used a color measurement device with CIEL*a* ${ }^{*}$ scoring system. Bersezio et al. [17] used both methods. All authors using a Vita scale arranged it by value order, from lightest to darkest (from 1 to 16). The longest follow-up time was of 25 years [8].

Table 3 presents the main results of the studies included in this systematic review. 
Table 3. Main results of the study analysis.

\begin{tabular}{|c|c|c|c|}
\hline Author, Year & Type of Study & Intervention (n) & Results \\
\hline Amato et al. [8], 2018 & Cohort & $\begin{array}{l}\text { Inside-outside } 10 \% \text { CP } 30 \mathrm{~min} \\
\text { in-office + Walking-Bleach } 10 \% \text { CP } \\
1 \times / \text { week, at least } 4 \times(n=40)\end{array}$ & $\begin{array}{l}\text { "An optimal tooth color stability in relation } \\
\text { to adjacent teeth was evidenced in } 34 \\
\text { patients, while six patients were classified } \\
\text { as failures, since a color mismatch of two or } \\
\text { more shades was noticed." "A success rate } \\
\text { of } 85 \% \text { was reported after } 25 \text { years." } \\
\text { End of treatment* } \\
\text { Follow-up ( } 25 \text { years) * }\end{array}$ \\
\hline Bersezio et al. [18], 2018 & RCT & $\begin{array}{l}\text { G1: Walking-bleach } 35 \% \mathrm{HP}, 4 \\
\text { sessions, } 1 \times / \text { week }(n=19) \\
\text { G2: Walking bleach } 37 \% \mathrm{CP}, 4 \\
\text { sessions, } 1 \times / \text { week }(n=19)\end{array}$ & $\begin{array}{l}\text { After bleaching: } \\
\text { G1: } \Delta \mathrm{E}=16.65 \pm 6.76, \mathrm{G} 2: \Delta \mathrm{E}=13.01 \pm 4.71 \\
1 \text { month after bleaching: } \\
\mathrm{G} 1: \Delta \mathrm{E}=15.01 \pm 5.01, \mathrm{G} 2: \Delta \mathrm{E}=13.62 \pm 5.13 \\
\text { 6 months after bleaching: } \\
\mathrm{G} 1: \Delta \mathrm{E}=14.53 \pm 5.07, \mathrm{G} 2: \Delta \mathrm{E}=14.09 \pm 6.61\end{array}$ \\
\hline Lise et al. [13], 2018 & RCT & $\begin{array}{l}\text { G1: Walking-bleach SP }+20 \% \mathrm{HP}, 4 \\
\text { sessions, } 1 \times / \text { week }(n=9) \\
\text { G2: Inside-outside } 10 \% \mathrm{CP}, 1 \text { h/day, } \\
4 \text { weeks }(n=8)\end{array}$ & $\begin{array}{l}\text { Immediate post bleaching evaluation: } \\
\text { G1: } \Delta \mathrm{E}=12.4 \pm 3.4^{*} ; \mathrm{I}-\mathrm{O}: \Delta \mathrm{E}=12.7 \pm 5.9^{*} \\
1 \text { year post bleaching evaluation: } \\
\mathrm{G} 2: \Delta \mathrm{E}=11.3 \pm 3.9^{*} \text {; } \mathrm{I}-\mathrm{O}: \Delta \mathrm{E}=10.9 \pm 3.3^{*}\end{array}$ \\
\hline Gupta et al. [21], 2014 & Cohort & $\begin{array}{l}\text { Walking-bleach } \\
\text { SP }+ \text { distilled water, } 1 \times / \text { week } \\
(n=41) \text {, until satisfactory results } \\
\text { were achieved, up to } 5 \text { sessions }\end{array}$ & $\begin{array}{l}\text { Post bleaching evaluation: } \\
\Delta S G U=11.76\end{array}$ \\
\hline Koçak et al. [22], 2014 & RCT & $\begin{array}{l}\text { Walking-bleach } \\
\text { G1: SP + distilled water }+60^{\prime} \text { LED } \\
\text { light }\left(1200 \mathrm{~mW} / \mathrm{cm}^{2}\right)(n=15) \\
\text { G2: } \mathrm{SP}+\text { distilled water }+60^{\prime} \text { diode } \\
\text { LASER }(7 \mathrm{~W} \text {, continuous }(n=15) \text {, } \\
\text { up to } 3 \times \text {, spaced by } 2 \text { days }\end{array}$ & $\begin{array}{l}\text { Post bleaching evaluation: } \\
\text { G1: } \Delta \mathrm{E}=8.67 \pm 1.885 \\
\mathrm{G} 2: \Delta \mathrm{E}=8.74 \pm 1.847\end{array}$ \\
\hline Umanah et al. [14], 2013 & RCT & $\begin{array}{l}\text { Walking-bleach } \\
\text { G1: } 35 \% \mathrm{CP}(n=38) \\
\text { G2: SP + distilled water }(n=38) \\
\text { Sessions spaced by } 5 \text { days, until } \\
\text { color matches the control's tooth or } \\
\text { no further changes occurs }\end{array}$ & $\begin{array}{l}\text { G1 } \triangle \text { SGU: } 1 \text { st session: } 5.87 \pm 1.88 ; 2 \text { nd } \\
\text { session: } 4.60 \pm 1.56 \text {; } 3 \text { rd session: } 1.27 \pm 1.62 \\
\text { G2 } \Delta \text { SGU: } 1 \text { st session: } 4.50 \pm 1.64 ; 2 \text { nd } \\
\text { session: } 5.84 \pm 2.09 ; \text { rd session: } 2.42 \pm 1.38\end{array}$ \\
\hline Deliperi [20], 2008 & Cohort & $\begin{array}{l}\text { Inside-outside } \\
35 \% \mathrm{HP} 30 \text { min in office } \\
+10 \% \mathrm{CP} \text { at home (duration not } \\
\text { specified) }(n=25)\end{array}$ & $\begin{array}{l}2 \text { weeks after treatment: } \Delta \text { SGU: } 1.6 \pm 0.7^{*} \\
\text { 2-year: } \Delta \text { SGU: } 2.8 \pm 1.7^{*} \\
\text { 5-year: } \Delta \text { SGU: } 3.4 \pm 2.0^{*}\end{array}$ \\
\hline Bizhang et al. [19], 2003 & RCT & $\begin{array}{l}\text { G1: Walking-bleach } \mathrm{SP}+3 \% \mathrm{HP} \\
1 \times / \text { week, } 4 \text { weeks }(n=20) \\
\text { G2: Inside-outside } 10 \% \mathrm{CP}, 3 \mathrm{~h} / \text { day } \\
+ \text { nocturnal use, } 11 \text { days }(n=21)\end{array}$ & $\begin{array}{l}\text { Immediate post bleaching evaluation: } \\
\mathrm{G} 1: \Delta \mathrm{E}=8.28 \pm 5.01 ; \mathrm{G} 2: \Delta \mathrm{E}=14.66 \pm 9.67 \\
6 \text { months post bleaching evaluation: } \\
\mathrm{G} 1: \Delta \mathrm{E}=6.63 \pm 4.20 ; \mathrm{G} 2: \Delta \mathrm{E}=8.17 \pm 3.29\end{array}$ \\
\hline
\end{tabular}

\subsection{Methodological Quality Assessment of Included Studies}

The results of the quality assessment of randomized clinical studies (RCTs) of the systematic reviews can be seen in Figure 2. Blinding intervention of participants and personnel as well as blinding evaluation of the results was impossible in most studies. Attrition bias and reporting bias were a minimal risk. Four studies $[14,19,21,22]$ were considered of fair or poor quality because three or more criteria were not met or were unclear, with high risk of bias. Two studies $[13,18]$ were considered of high quality, because all criteria had low risk of bias. 

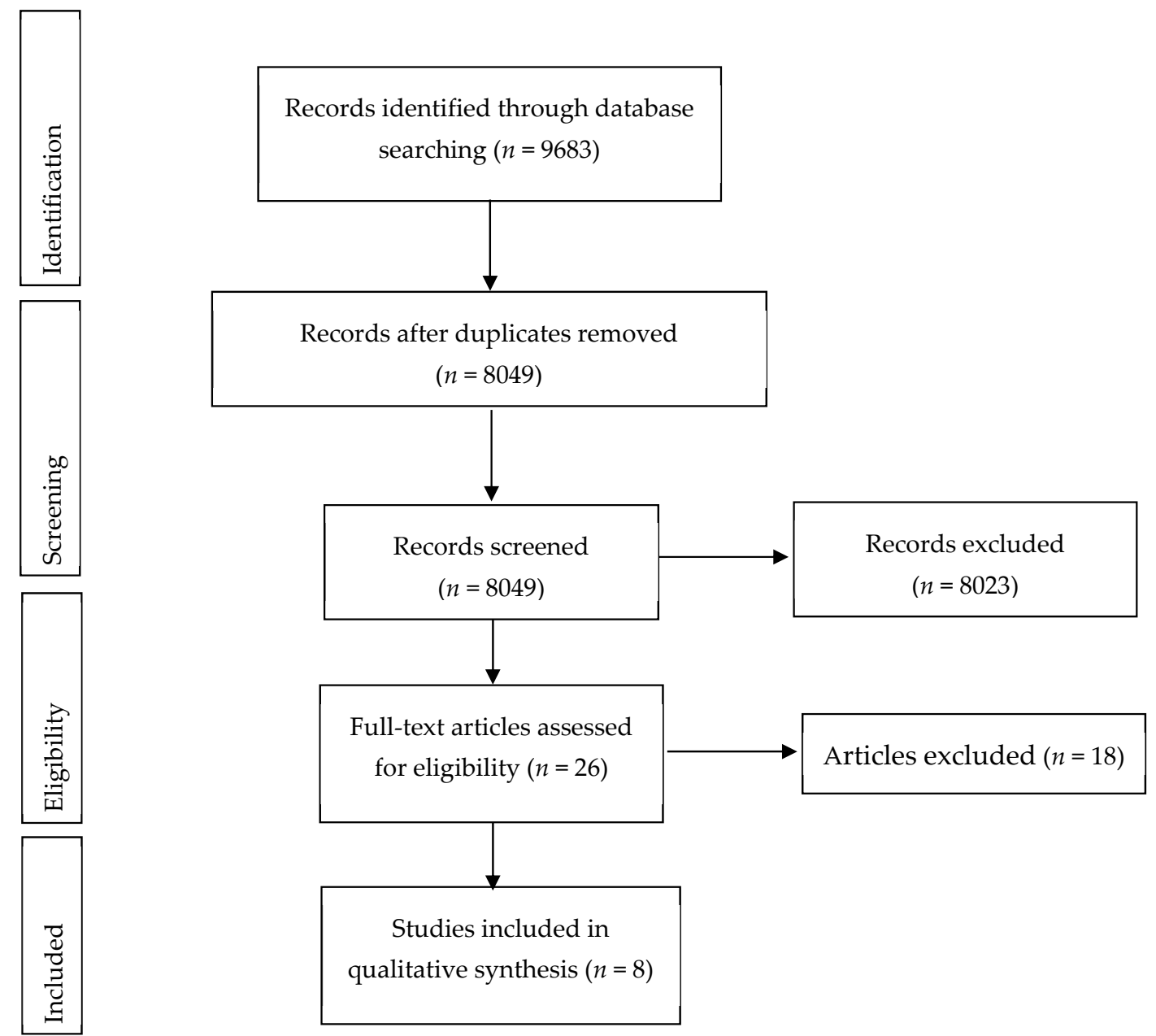

Figure 1. Flow diagram of study selection.

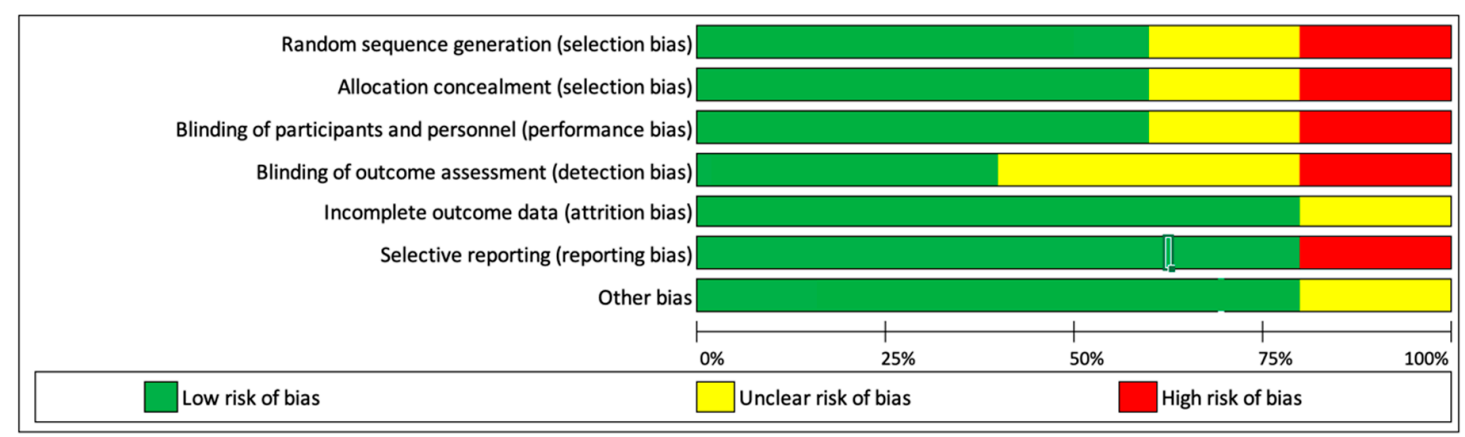

Figure 2. Risk of bias of the included randomized clinical trials.

Regarding the quality assessment of the cohort studies, results can be seen in Table 4 . The pre-intervention bias was considered to be of low risk since, in all three studies, there was no confounding biases and the selection of participants was well explained. At intervention, all studies provided enough information regarding all procedures, being this domain also considered to be of low risk of bias. The post-intervention bias was low to moderate risk, because there was some data missing from one of the studies. 
Table 4. Risk of bias of the included cohort studies.

\begin{tabular}{|c|c|c|c|c|c|c|c|}
\hline \multicolumn{2}{|c|}{ Pre-Intervention } & \multirow{2}{*}{$\begin{array}{c}\text { At Intervention } \\
\text { Bias in } \\
\text { Classification of } \\
\text { Interventions }\end{array}$} & \multicolumn{4}{|c|}{ Post-Intervention } & \multirow[t]{2}{*}{$\begin{array}{c}\text { Non-Randomized } \\
\text { Studies of Interventions }\end{array}$} \\
\hline $\begin{array}{l}\text { Bias Due to } \\
\text { Confounding }\end{array}$ & $\begin{array}{l}\text { Bias in Selection } \\
\text { of Participants } \\
\text { into the Study }\end{array}$ & & $\begin{array}{l}\text { Bias due to } \\
\text { Deviations from } \\
\text { Intended } \\
\text { Interventions }\end{array}$ & $\begin{array}{l}\text { Bias Due to } \\
\text { Missing Data }\end{array}$ & $\begin{array}{c}\text { Bias in } \\
\text { Measurement of } \\
\text { Outcomes }\end{array}$ & $\begin{array}{c}\text { Bias in Selection } \\
\text { of the Reported } \\
\text { Result }\end{array}$ & \\
\hline $\mathrm{Y} / \mathrm{PY} / \mathrm{PN} / \mathrm{N} / \mathrm{NI}$ & $\mathrm{Y} / \mathrm{PY} / \mathrm{PN} / \mathrm{N} / \mathrm{NI}$ & $\mathrm{Y} / \mathrm{PY} / \mathrm{PN} / \mathrm{N} / \mathrm{NI}$ & $\mathrm{Y} / \mathrm{PY} / \mathrm{PN} / \mathrm{N} / \mathrm{NI}$ & $\mathrm{Y} / \mathrm{PY} / \mathrm{PN} / \mathrm{N} / \mathrm{NI}$ & Y/PY/PN/N/NI & $\mathrm{Y} / \mathrm{PY} / \mathrm{PN} / \mathrm{N} / \mathrm{NI}$ & Amato et al. [8], 2018 \\
\hline $\mathrm{Y} / \mathrm{PY} / \mathrm{PN} / \mathrm{N} / \mathrm{NI}$ & Y/PY/PN/N/NI & Y/PY/PN/N/NI & $\mathrm{Y} / \mathrm{PY} / \mathrm{PN} / \mathrm{N} / \mathrm{NI}$ & $\mathrm{Y} / \mathrm{PY} / \mathrm{PN} / \mathrm{N} / \mathrm{NI}$ & $\mathrm{Y} / \mathrm{PY} / \mathrm{PN} / \mathrm{N} / \mathrm{NI}$ & $\mathrm{Y} / \mathrm{PY} / \mathrm{PN} / \mathrm{N} / \mathrm{NI}$ & Deliperi et al. [20], 2008 \\
\hline $\mathrm{Y} / \mathrm{PY} / \mathrm{PN} / \mathrm{N} / \mathrm{NI}$ & $\mathrm{Y} / \mathrm{PY} / \mathrm{PN} / \mathrm{N} / \mathrm{NI}$ & $\mathrm{Y} / \mathrm{PY} / \mathrm{PN} / \mathrm{N} / \mathrm{NI}$ & $\mathrm{Y} / \mathrm{PY} / \mathrm{PN} / \mathrm{N} / \mathrm{NI}$ & Y/PY/PN/N/NI & Y/PY/PN/N/NI & Y/PY/PN/N/NI & Gupta et al. [21], 2014 \\
\hline Low risk & Low risk & Low risk & Low risk & Moderate risk & Low risk & Low risk & $\begin{array}{l}\text { RISK OF BIAS } \\
\text { JUDGEMENT }\end{array}$ \\
\hline
\end{tabular}

Risk of bias-(Y) Yes; (PY) probably yes; (PN) probably no; (N) no; (NI) no information. 


\section{Discussion}

Studies have shown that in order to consider a tooth whitening procedure effective, there needs to be a change of at least 5 units of $\Delta \mathrm{E}$ [23]. Thus, it was found that the walking-bleach and the combined techniques were effective at the end of the treatment, obtaining similar aesthetic results $[13,20,23]$.

When compared to the walking-bleach technique, the combined technique has several advantages, such as the patient's control over the bleaching effect, which may prevent over-bleaching; a reduced number of appointments and chair time, which translates to a lower treatment cost; and shorter treatment time, which reduces exposure to the bleaching agent, minimizing possible future sequelae $[13,19]$.

Gupta et al. [21] reported two withdrawals during the treatment with the walking-bleach technique, with the main factor of dissatisfaction referred being the need for multiple visits. The same author verified that older patients or older discolorations required a longer treatment period. However, the severity of discoloration did not influence the number of appointments required.

The drawbacks of the combined technique, in comparison to the walking-bleach technique, are that the cavity remains open during treatment, which represents an increased risk of fracture, and the need for patient cooperation, both during treatment and at the end, since it is necessary to return to the office to perform the final restoration $[13,19]$.

Bizhang et al. [19] reported that the immediate aesthetic results of the combined technique were superior to those of the walking-bleach technique. However, at 6 months recall this difference was not significant, and the techniques were equally effective. Berzebio et al. [18] reported a slight color regression, one month after completion of treatment, as did Bizhang et al. [19] at the six-month recall, and Lise et al. [13] at the one-year evaluation. This can be explained by the rehydration of the tooth. For this reason, some authors are led to consider overwhitening in order to compensate for the chromatic regression [23]. Recurrence is relatively common in intracoronary bleaching and depends on the time elapsed after its completion. The walking-bleach technique has variable failure rates between $10 \%, 25 \%$, and $49 \%$ after 2,5 , and 8 years, respectively $[13,19]$. There are currently no studies of long-term relapse associated with the combined technique.

At the time of the last check-up, performed 1 year after treatment completion, Lise et al. [13] had no root resorption occurrences to report. The remaining studies did not perform this control. However, this is a possible side effect of internal tooth bleaching, which should be minimized as much as possible. Studies show that cervical root resorption can be avoided or decreased with the placement of a cervical biomechanical barrier. Thus, in both walking-bleach and combined techniques, $3 \mathrm{~mm}$ of the canal filling material should be removed apical to amelocemental junction and a layer of calcium hydroxide covered with a layer of glass ionomer cement should be placed $[4,8,13]$. The purpose of this barrier is to prevent diffusion of the bleaching agent through the dentinal tubules, and to infiltrate through the root canal to the periapical region [19]. Other forms of prevention include the placement of calcium hydroxide in the pulp chamber after the end of bleaching, the buffering of which enables the neutralization of the $\mathrm{pH}$ decrease caused by hydrogen peroxide $[13,19]$. The function of polymorphonuclear leukocytes, as well as osteoclasts, is described as being more noticeable in slightly acidic environments. Their action is characterized by the promotion of acidic hydrolysis, which results in demineralization of hard tissue components and prevention of formation of new hard tissues. Hence, external cervical root resorption may occur if the $\mathrm{pH}$ change happens in the microenvironment of the cervical periodontal ligament. Thirty percent of hydrogen peroxide has a $\mathrm{pH}$ value of $2-3$. Ten percent carbamide peroxide decomposes to $3.35 \%$ hydrogen peroxide and $6.65 \%$ urea solution, which results in an increase in $\mathrm{pH}$ and, therefore, greater clinical safety [19]. Sodium perborate has a $\mathrm{pH}$ value of 10-12 [19], which has led some authors to use this agent as an alternative to hydrogen peroxide, or to combine this substance with hydrogen peroxide in low concentrations, in order to counteract the change of $\mathrm{pH}$ induced by hydrogen peroxide and therefore minimize external root resorptions [22].

It should be noted that, in the studies analyzed, the concentrations of bleaching agent used in the walking-bleach technique (20\% [13] and 35\% [23] hydrogen peroxide, 35\% [14] and 37\% [23] carbamide peroxide) are much higher than those used in the combined technique ( $10 \%$ carbamide 
peroxide $[8,13,19,20])$. This is probably due to the bleaching agent replacement regime, which occurs daily in the combined technique, requiring lower concentrations, and weekly in the walking-bleach technique, requiring higher concentrations. So, if both techniques present equivalent results, lower concentrations should be preferred, minimizing possible secondary effects.

For safety reasons, in 2009 the European Union regulated that the use of cosmetic substances classified as carcinogenic, mutagenic, or toxic to reproduction should be assessed, taking all sources of exposure into account. Since the borate family is included in this classification, its use in cosmetic products, including tooth whitening products, was banned from the European Union from 1 December 2010, with no exceptions [24]. For clinical safety purposes, the European Union banned the use of hydrogen peroxide and other compounds or mixtures, which release hydrogen peroxide, including carbamide peroxide, in concentrations higher than $6 \%$. It also regulated that dental bleaching products available over the counter cannot have hydrogen peroxide concentrations greater than $0.1 \%$, and dental bleaching products with concentrations between $0.1 \%$ and $6 \%$ are to be sold exclusively to dentists, from 2011 [25].

\section{Conclusions}

Regardless of the technique used, internal bleaching is a conservative, simple, effective, and low-cost procedure, with good esthetic results, in the treatment of non-vital tooth discolorations. The cervical barrier is a standard of care in internal bleaching techniques and should be used. Considering the similarity in the esthetic results obtained in both techniques, the concentrations used for both, and since the biocompatibility of the bleaching agent was more important than its efficiency or speed in obtaining results, the combined technique should be adopted in preference to the walking-bleach technique.

Author Contributions: Conceptualization, A.S.C. and A.P.; methodology, A.S.C., C.M.M., I.A., E.C., A.P.; data analysis, A.S.C., L.G., M.M., A.P.; writing—original draft preparation, A.S.C., L.G., M.M., A.P.; writing一review and editing, A.S.C., I.A., C.M.M., E.C., A.P. All authors have read and agreed to the published version of the manuscript.

Funding: This research received no external funding.

Acknowledgments: A thank you note to Helena Donato, Director of the Documentation Center of the Hospital and University Center of Coimbra.

Conflicts of Interest: The authors declare no conflict of interest.

\section{References}

1. Joiner, A.; Luo, W. Tooth colour and whiteness: A review. J. Dent. 2017, 67S, S3-S10. [CrossRef]

2. Montero, J.; Gomez-Polo, C.; Santos, J.A.; Portillo, M.; Lorenzo, M.C.; Albaladejo, A. Contributions of dental colour to the physical attractiveness stereotype. J. Oral Rehabil. 2014, 41, 768-782. [CrossRef] [PubMed]

3. Al-Zarea, B.K. Satisfaction with appearance and the desired treatment to improve aesthetics. Int. J. Dent. 2013, 2013, 912368. [CrossRef] [PubMed]

4. Zimmerli, B.; Jeger, F.; Lussi, A. Bleaching of nonvital teeth. A clinically relevant literature review. Schweiz. Mon. Zahnmed. 2010, 120, 306-320.

5. Plotino, G.; Buono, L.; Grande, N.M.; Pameijer, C.H.; Somma, F. Nonvital tooth bleaching: A review of the literature and clinical procedures. J. Endod. 2008, 34, 394-407. [CrossRef] [PubMed]

6. Attin, T.; Paque, F.; Ajam, F.; Lennon, A.M. Review of the current status of tooth whitening with the walking bleach technique. Int. Endod. J. 2003, 36, 313-329. [CrossRef] [PubMed]

7. Spasser, H.F. A simple bleaching technique using sodium perborate. N. Y. State Dent. J. 1961, 27, 332-334.

8. Amato, A.; Caggiano, M.; Pantaleo, G.; Amato, M. In-office and walking bleach dental treatments on endodontically-treated teeth: 25 years follow-up. Minerva Stomatol. 2018, 67, 225-230. [CrossRef]

9. Settembrini, L.; Gultz, J.; Kaim, J.; Scherer, W. A technique for bleaching nonvital teeth: Inside/outside bleaching. J. Am. Dent. Assoc. 1997, 128, 1283-1284. [CrossRef] 
10. Poyser, N.J.; Kelleher, M.G.; Briggs, P.F. Managing discoloured non-vital teeth: The inside/outside bleaching technique. Dent. Update 2004, 31, 204-210, 213-214. [CrossRef]

11. Kwon, S.R.; Wertz, P.W. Review of the Mechanism of Tooth Whitening. J. Esthet. Restor. Dent. 2015, 27, 240-257. [CrossRef] [PubMed]

12. Lo Giudice, R.; Pantaleo, G.; Lizio, A.; Romeo, U.; Castiello, G.; Spagnuolo, G.; Lo Giudice, G. Clinical and Spectrophotometric Evaluation of LED and Laser Activated Teeth Bleaching. Open Dent. J. 2016, 10, 242-250. [CrossRef] [PubMed]

13. Lise, D.P.; Siedschlag, G.; Bernardon, J.K.; Baratieri, L.N. Randomized clinical trial of 2 nonvital tooth bleaching techniques: A 1-year follow-up. J. Prosthet. Dent. 2018, 119, 53-59. [CrossRef] [PubMed]

14. Umanah, A.U.; Sede, M.A.; Ibhawoh, L.O. Clinical efficacy of 35\% carbamide peroxide and sodium perborate in intracoronal bleaching of discoloured non-vital teeth. J. Med. Biomed. Res. 2013, 12, 96-104.

15. Chng, H.K.; Palamara, J.E.; Messer, H.H. Effect of hydrogen peroxide and sodium perborate on biomechanical properties of human dentin. J. Endod. 2002, 28, 62-67. [CrossRef]

16. Carrasco, L.D.; Froner, I.C.; Corona, S.A.; Pecora, J.D. Effect of internal bleaching agents on dentinal permeability of non-vital teeth: Quantitative assessment. Dent. Traumatol. 2003, 19, 85-89. [CrossRef]

17. Higgins, J.P.T.; Green, S. Cochrane Handbook for Systematic Reviews of Interventions (version 5.1.0). Available online: Handbook-5-1.cochrane.org (accessed on 11 November 2019).

18. Bersezio, C.; Ledezma, P.; Mayer, C.; Rivera, O.; Junior, O.B.O.; Fernandez, E. Effectiveness and effect of non-vital bleaching on the quality of life of patients up to 6 months post-treatment: A randomized clinical trial. Clin. Oral Investig. 2018, 22, 3013-3019. [CrossRef]

19. Bizhang, M.; Heiden, A.; Blunck, U.; Zimmer, S.; Seemann, R.; Roulet, J.F. Intracoronal bleaching of discolored non-vital teeth. Oper. Dent. 2003, 28, 334-340.

20. Deliperi, S. Clinical evaluation of nonvital tooth whitening and composite resin restorations: Five-year results. Eur. J. Esthet. Dent. 2008, 3, 148-159.

21. Gupta, S.K.; Saxena, P. Evaluation of patient satisfaction after non-vital bleaching in traumatized discolored intact anterior teeth. Dent. Traumatol. 2014, 30, 396-399. [CrossRef]

22. Kocak, S.; Kocak, M.M.; Saglam, B.C. Clinical comparison between the bleaching efficacy of light-emitting diode and diode laser with sodium perborate. Aust. Endod. J. 2014, 40, 17-20. [CrossRef] [PubMed]

23. Bersezio, C.; Martin, J.; Pena, F.; Rubio, M.; Estay, J.; Vernal, R.; Junior, O.O.; Fernandez, E. Effectiveness and Impact of the Walking Bleach Technique on Esthetic Self-perception and Psychosocial Factors: A Randomized Double-blind Clinical Trial. Oper. Dent. 2017, 42, 596-605. [CrossRef] [PubMed]

24. Diniz, M.B.; Lima, L.M.; Santos-Pinto, L.; Eckert, G.J.; Zandona, A.G.; de Cassia Loiola Cordeiro, R. Influence of the ICDAS e-learning program for occlusal caries detection on dental students. J. Dent. Educ. 2010, 74, 862-868.

25. Mitropoulos, P.; Rahiotis, C.; Stamatakis, H.; Kakaboura, A. Diagnostic performance of the visual caries classification system ICDAS II versus radiography and micro-computed tomography for proximal caries detection: An in vitro study. J. Dent. 2010, 38, 859-867. [CrossRef]

(C) 2020 by the authors. Licensee MDPI, Basel, Switzerland. This article is an open access article distributed under the terms and conditions of the Creative Commons Attribution (CC BY) license (http://creativecommons.org/licenses/by/4.0/). 